\section{Carotid plaque burden is associated with higher levels of total homocysteine}

There are several problems with the report of Li et al. ${ }^{1}$ They studied sex differences, not gender differences. ${ }^{2}$ They referred to carotid intima-media thickness (IMT) as atherosclerosis; it is not, and plaque burden is a much stronger predictor of cardiovascular risk than IMT. ${ }^{3}$ They referred to levels of homocysteine (Hcy), but almost certainly what they measured was total homocysteine ( $\mathrm{tHcy}$ ), which includes homocysteine, its dimer homocystine and mixed homocysteine/cysteine disulfide. ${ }^{4}$ Their conclusion that homocysteine levels are not associated with carotid atherosclerosis is invalid, because (a) they did not measure atherosclerosis; they only identified the presence or absence of plaque and (b) the range of homocysteine levels they studied was above the threshold for increased plaque with increasing levels of tHcy, as previously reported. ${ }^{5}$

Figure 1 shows the total plaque area in 2635 patients in my clinic database with levels of tHcy grouped as $<10$

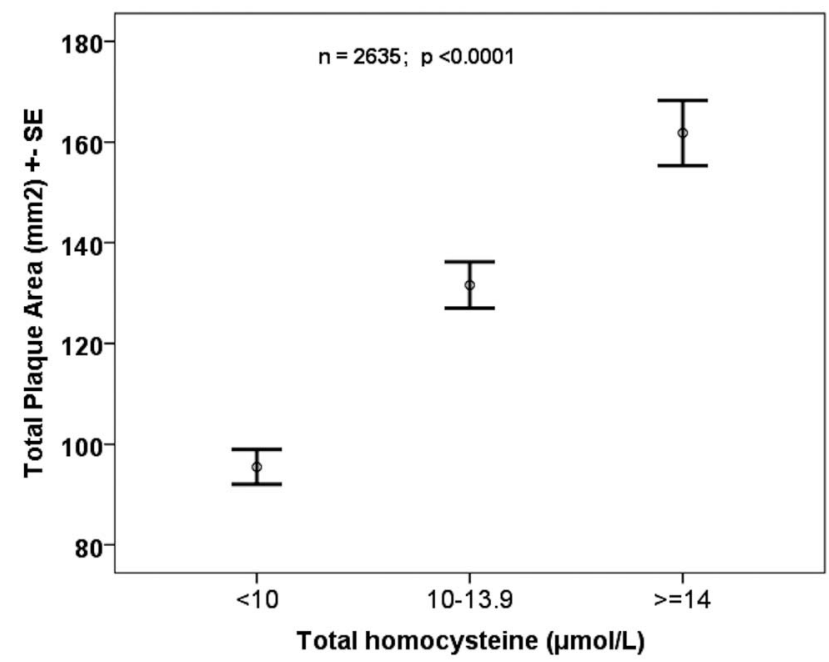

Figure 1 Among 2635 patients in the database of vascular prevention clinics, higher tHcy was associated significantly with higher total plaque area $(p<0.0001 ; A N O V A)$. ANOVA, analysis of variance; tHcy, total homocysteine. $(\mathrm{n}=1296), 10-13.9 \quad(\mathrm{n}=837)$, and $>14 \mu \mathrm{mol} / \mathrm{L} \quad(\mathrm{n}=502)$. Plaque burden was significantly greater with higher levels of plasma tHcy $(\mathrm{p}<0.0001)$.

The authors should reanalyse their data using lower thresholds of tHcy: something like $<10,10-13.9$ and $>14 \mu \mathrm{mol}$.

\section{J David Spence}

Stroke Prevention \& Atherosclerosis Research Centre, Robarts Research Institute, Western University, London, Ontario, Canada

Correspondence to Dr J David Spence; dspence@robarts.ca

Contributors The letter was written and the figure composed by JDS.

Competing interests JDS is an officer of Vascularis.

Ethics approval University of Western Ontario Human Subjects Research Ethics Board.

Provenance and peer review Not commissioned; internally peer reviewed.

Data sharing statement Data may only be shared with approval of the University of Western Ontario Human Subjects Research Ethics Board.

Open Access This is an Open Access article distributed in accordance with the Creative Commons Attribution Non Commercial (CC BY-NC 4.0) license, which permits others to distribute, remix, adapt, build upon this work noncommercially, and license their derivative works on different terms, provided the original work is properly cited and the use is non-commercial. See: http:// creativecommons.org/licenses/by-nc/4.0/

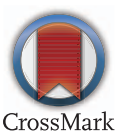

To cite: Spence JD. Carotid plaque burden is associated with higher levels of total homocysteine. Stroke and Vascular Neurology 2017;2:e000076. doi:10.1136/svn-2017-000076

Received 6 February 2017

Accepted 7 February 2017

\section{REFERENCES}

1. Li Y, Zhang W, Fang Y, et al. No association between elevated homocysteine levels and carotid atherosclerosis in a rural population in China. Stroke Vasc Neurol 2016;1:154-60.

2. Spence JD, Pilote L. Importance of sex and gender in atherosclerosis and cardiovascular disease. Atherosclerosis 2015;241:208-10.

3. Spence JD. Carotid ultrasound phenotypes are biologically distinct. Arterioscler Thromb Vasc Biol 2015;35:1910-13.

4. Mudd SH, Finkelstein JD, Refsum H, et al. Homocysteine and its disulfide derivatives: a suggested consensus terminology. Arterioscler Thromb Vasc Biol 2000;20:1704-6.

5. Robertson J, lemolo F, Stabler SP, et al. Vitamin B12, homocysteine and carotid plaque in the era of folic acid fortification of enriched cereal grain products. CMAJ 2005;172:1569-73. 